\title{
Analisa Pengaruh Penempatan Slip Terhadap Distribusi Tekanan, Load Support, dan Friction pada Journal Bearing
}

\author{
Muchammad \\ Departemen Teknik Mesin, Fakultas Teknik, Universitas Diponegoro \\ Jl. Prof. Sudharto, SH., Tembalang-Semarang 50275, Telp. +62247460059 \\ E-mail: m_mad5373@yahoo.com
}

\begin{abstract}
Lubrication on the bearings useful to reduce friction by separating the components between solid and solid. One of the bearings that uses fluid as a lubricant or separator is a journal bearing. Improved lubrication performance in journaling bearing can be achieved by slip on solid surface, slip phenomenon increases pressure distribution in lubricant which surely raises load support and decreases friction in film lubricant. In this paper, the contact case on journal bearing is modeled by unwrapped journal bearing and solved by CFD (Computational Fluid Dynamic). The slip equation is made through User-Defined Function (UDF) programming. Based on the result of variation of slip, the highest load support on eccentricity $(\varepsilon) 0.2$ and $\varepsilon 0.4$ which slip area on $\varepsilon 0.2$ is $0^{\circ}-240^{\circ}$ and slip area on $\varepsilon 0.4$ is $0^{\circ}-210^{\circ}$. While the smallest friction occurs on $\varepsilon 0.2$ which slip area is $0^{\circ}-300^{\circ}, \varepsilon 0.4$ which slip area is $0^{\circ}-270^{\circ}, \varepsilon 0.6$ which slip area is $0^{\circ}-240^{\circ}$ and $\varepsilon 0.8$ which slip area $0^{\circ}-210^{\circ}$.
\end{abstract}

Keyword: journal bearing;lubrication performance; slip; User-Defined Function

\begin{abstract}
Abstrak
Pelumasan pada bearing sangat berpengaruh untuk mengurangi gesekan dengan memisahkan komponen antara solid dan solid. Salah satu bearing yang menggunakan fluida sebagai pelumas atau pemisahnya adalah journal bearing. Peningkatan performa pelumasan pada journal bearing dapat dilakukan dengan pemberian slip pada permukaan solid, pemberian slip dapat meningkatkan tekanan pelumas yang tentunya menaikkan load support dan menurunkan friction pada fluid film. Dalam penelitian ini, kasus kontak journal bearing dimodelkan dengan unwrapped journal bearing. Pemodelan dipecahkan dengan menggunakan software CFD. Persamaan slip akan dibuat melalui pemrograman User-Defined Function (UDF) untuk memecahkan studi kasus tentang fenomena slip. Berdasarkan hasil dari variasi pemberian slip, nilai load support tertinggi pada $\varepsilon 0.2$ dan $\varepsilon 0.4$ dengan penempatan slip untuk $\varepsilon 0.2$ pada slip $0^{\circ}-240^{\circ}$ dan $\varepsilon 0.4$ pada slip $0^{\circ}-210^{\circ}$. Sedangkan friction terkecil terjadi pada $\varepsilon 0.2$ pada slip $0^{\circ}-300^{\circ}$, $\varepsilon 0.4$ pada slip $0^{\circ}-270^{\circ}, \varepsilon 0.6$ pada slip $0^{\circ}-240^{\circ}$ dan $\varepsilon 0.8$ pada slip $0^{\circ}-210^{\circ}$.
\end{abstract}

Kata kunci: journal bearing; performa pelumasan; slip; User-Defined Function

\section{Pendahuluan}

Dalam ilmu mekanika bearing adalah sebuah elemen mesin yang berfungsi untuk membatasi gerak relatif antara dua atau lebih komponen mesin agar selalu bergerak pada arah yang diinginkan. Bearing menjaga poros (shaft) agar selalu berputar terhadap sumbu porosnya, atau juga menjaga suatu komponen yang bergerak linier agar selalu berada pada jalurnya. Antar permukaan dalam bearing dapat dipisahkan dengan fluida ataupun komponen lainnya seperti bola dan rol. Salah satu bearing yang menggunakan fluida sebagai pemisahnya adalah journal bearing.

Journal bearing merupakan pendukung poros dalam kondisi radial atau berputar. Journal bearing terdiri dari dua bagian utama, yaitu poros (shaft) dan lubang silinder (housing) seperti pada gambar 1. Poros dikenal sebagai journal dan lubang silinder sebagai bearing. Poros yang berbantalan luncur dapat menghasilkan putaran yang sangat tinggi sehingga untuk meredam ayunan, kejutan maupun kebisingan dari putaran tersebut dapat menggunakan pelumasan dalam bentuk cair, padat maupun gas.

Kondisi batas aliran fluida merupakan salah satu faktor terpenting yang menentukan kinerja dan karakteristik hidrodinamik fluida. Dalam ilmu mekanika fluida klasik, digunakan persamaan Reynolds untuk mendeskripsikan aliran pelumasan. Turunan dari persamaan Reynolds ini biasanya didasarkan bahwa kondisi batas terjadi no-slip antara fluida dengan permukaan padat dan terjadi kecepatan gerakan relatif antara molekul fluida pada permukaan padat dan antarmuka padat sama dengan nol. Namun, dalam beberapa tahun terakhir, dengan pengembangan ilmu pengetahuan dan teknologi mikro-nanometer, ditemukan bahwa kondisi batas no-slip tidak lagi berlaku dalam kondisi tertentu. Selama akhir dekade ini telah ditemukan bahwa slip terjadi pada aliran. Slip selalu menyebabkan pengurangan gaya gesek dan meningkatkan daya dukung pada kondisi tertentu [2]. 


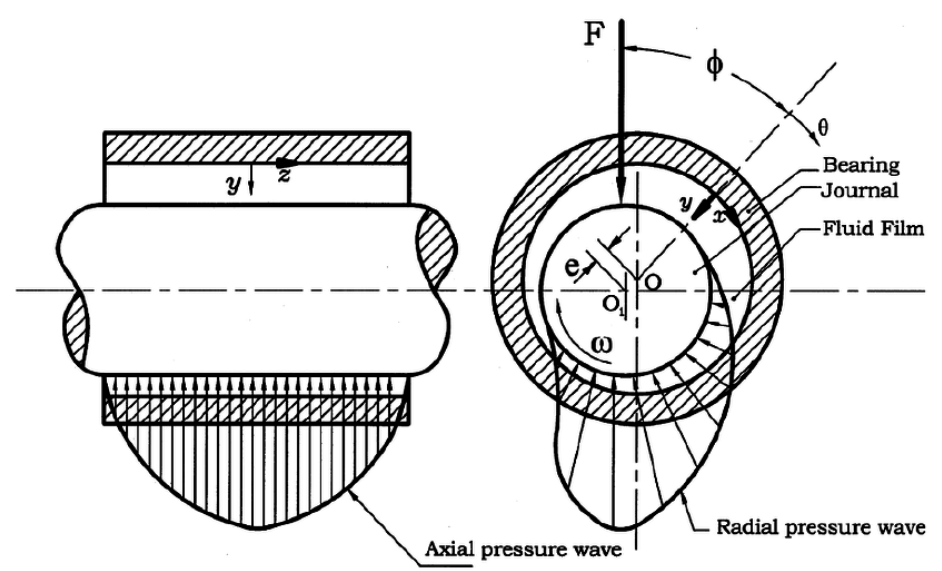

Gambar 1. Journal bearing [1]

Atas dasar pemikiran di atas maka akan dicari pengaruh distribusi tekanan, load support, dan friction dengan pelumasan air terhadap partial slip pada journal bearing sehingga bisa meningkatkan performansi pelumasan. Hal ini dilakukan untuk mengurangi waktu perawatan dan meningkatkan umur pakai journal bearing. Untuk pemecahan masalah ini solusi yang digunakan adalah dengan menggunakan softwere CFD.

\section{Metode Penelitian}

\subsection{Geometry dan Pendefinisian Masalah}

Journal bearing terdiri dari poros yang berputar relatif terhadap housing seperti yang dapat terlihat pada gambar 2 berikut. Fluida pelumasan mengisi celah diantara kedua permukaan tersebut untuk mencegah terjadinya kegagalan lubrikasi pada journal bearing.

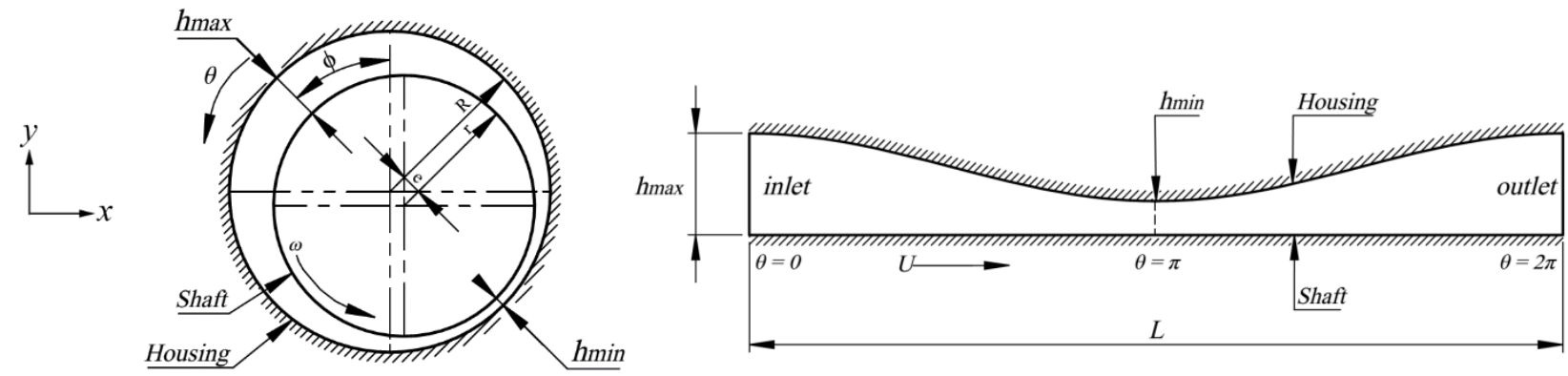

Gambar 2. Skema journal bearing dan pemodelan unwrapped journal bearing

Geometri journal bearing yang digunakan dalam mensimulasikan berbagai kasus aliran fluida journal bearing dalam penelitian ini mengadopsi geometri journal bearing milik Xie dkk. [13] dengan karakteristik geometri journal bearing dan karaktristik fluida pelumasan sebagai berikut.

Tabel 1. Parameter journal bearing

\begin{tabular}{lcc}
\hline Parameter & Simbol & Nilai \\
\hline Jari-jari poros & $r$ & $39.94 \mathrm{~mm}$ \\
Jari-jari housing & $R$ & $40 \mathrm{~mm}$ \\
Radial clearance & $C$ & $0.06 \mathrm{~mm}$ \\
Rasio eksentrisitas & $\varepsilon$ & $0.2,0.4,0.6 \mathrm{dan} 0.8$ \\
& & $0.012 \mathrm{~mm}(\varepsilon=0.2)$ \\
Eksentrisitas & $e$ & $0.024 \mathrm{~mm} \mathrm{( \varepsilon =0.4)}$ \\
& & $0.036 \mathrm{~mm}(\varepsilon=0.6)$ \\
Kecepatan angular journal & & $0.048 \mathrm{~mm}(\varepsilon=0.8)$ \\
Densitas lubrikan & $\omega$ & $1000 \mathrm{RPM}$ \\
Viskositas dinamis lubrikan & $\rho$ & $998.2 \mathrm{~kg} / \mathrm{m}^{3}$ \\
\hline
\end{tabular}


Meskipun dalam kondisi nyatanya journal bearing memiliki nilai panjang yang terdefinisi sebagai radial, namun dalam tugas akhir ini journal bearing akan dimodelkan sebagai linear journal bearing. Dengan demikian domain fluida pelumasan dari journal bearing dapat dimodelkan sebagai grafik fungsi kosinus seperti yang dapat dilihat pada gambar 4 berikut. Bagian housing dimodelkan sebagai profil stasioner periodik dengan panjang gelombang $L=2 \pi R$, sedangkan poros dari journal bearing dimodelkan sebagai permukaan datar yang bergerak dengan kecepatan $v=r \omega$. Untuk dapat memodelkan penyederhanaan domain fluida journal bearing seperti pada gambar 4 diatas, maka diperlukan persamaan matematis yang dapat digunakan untuk mendefiniskan bentuk profil stasioner periodik dari permukaan housing journal bearing. Persamaan matematis tersebut dapat diperoleh dengan melakukan perhitungan persamaan umum kurva kosinus sbb.

$$
\begin{array}{ll}
\text { Persamaan kurva } & : y=A \cdot \cos (b x)+c \\
\text { Amplitudo } & : A=\frac{h_{\max }-h_{\min }}{2} \\
\text { Konstanta b } & : b=\frac{2 \pi}{L} \\
\text { Konstanta c } & : c=A+h_{\min }
\end{array}
$$

Sedangkan kecepatan rotasional dan bilangan Reynold untuk aliran fluida pada journal bearing dapat diperoleh melalui persamaan berikut.

Kecepatan poros

$$
\begin{aligned}
& : v=\omega \cdot r=\left(\frac{2 \pi}{60} \cdot n\right) \cdot r=\left(\frac{2 \pi}{60} \cdot 1000\right) 0.04=4.18 \mathrm{~m} / \mathrm{s} \\
& : R e=\frac{U \rho C}{\mu}=\frac{(4.182)(998.2)\left(6 \times 10^{-5}\right)}{1.003 \times 10^{-3}}=249.7
\end{aligned}
$$

Bilangan Reynold

Dengan demikian hasil persamaan kurva pada setiap eksentrisitas sebagai berikut:

Tabel 2. Persamaan kurva pada setiap eksentrisitas rasio

\begin{tabular}{ccccc}
$\varepsilon$ & $e(\mathrm{~mm})$ & $h_{\max }(\mathrm{mm})$ & $h_{\min }(\mathrm{mm})$ & $y(x)(\mathrm{mm})$ \\
\hline 0.2 & 0.012 & 0.072 & 0.048 & $y=0.012 \cdot \cos (0.025 x)+0.06$ \\
0.4 & 0.024 & 0.084 & 0.036 & $y=0.024 \cdot \cos (0.025 x)+0.06$ \\
0.6 & 0.036 & 0.096 & 0.024 & $y=0.036 \cdot \cos (0.025 x)+0.06$ \\
0.8 & 0.048 & 0.108 & 0.012 & $y=0.048 \cdot \cos (0.025 x)+0.06$ \\
\hline
\end{tabular}

Adapun konfigurasi journal bearing beserta kasus yang akan dibahas dalam penelitian ini dapat dilihat pada tabel 3 berikut.

Tabel 3. Konfigurasi journal bearing yang akan digunakan

\begin{tabular}{ll}
\hline Kasus & Konfigurasi Journal bearing \\
\hline 1 & Validasi Journal bearing dengan kondisi noslip, slip $90^{\circ}$, dan slip $180^{\circ}$ pada eksentrisitas rasio 0.2 dan 0.8 \\
2 & $\begin{array}{l}\text { Journal bearing dengan kondisi no-slip, dan perkembangan slip dari sudut } 30^{\circ} \text { sampai full slip pada } \\
\text { eksentrisitas rasio 0.2, 0.4, 0.6 dan } 0.8\end{array}$ \\
\hline
\end{tabular}

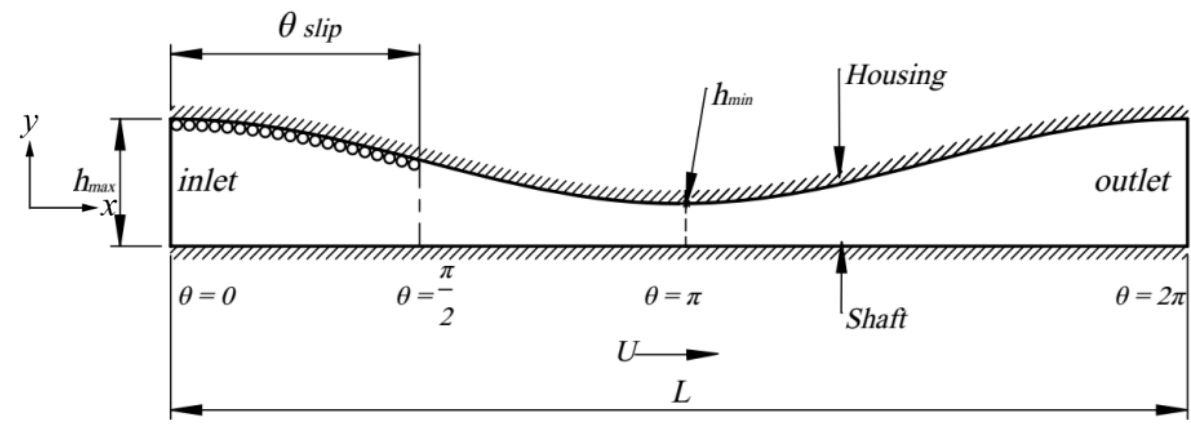

(a) 


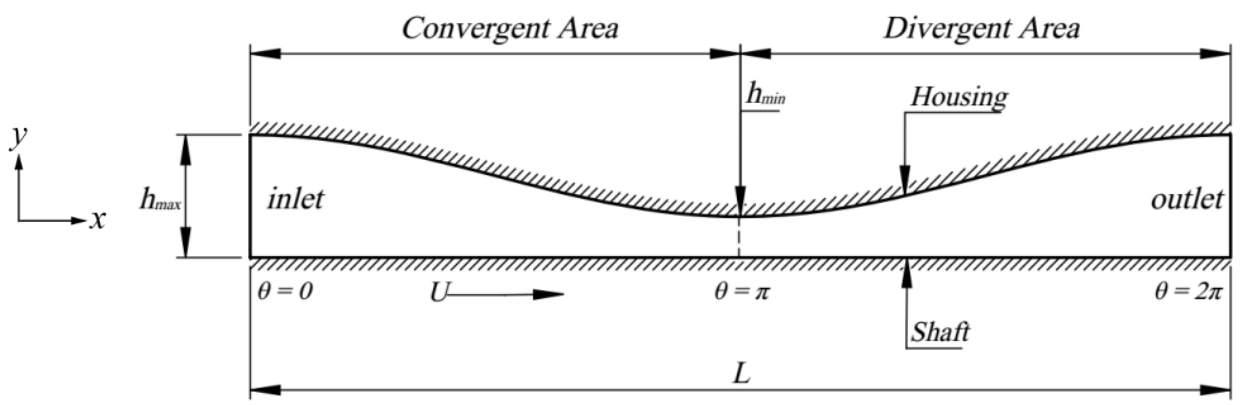

(b)

Gambar 3. (a) Journal bearing kondisi batas slip dan (b) Daerah convergent dan divergent pada journal bearing.

\subsection{Mesh independence check}

Sebelum melakukan validasi kasus, perlu dilakukan studi grid independent dari permodelan geometri yang telah dilakukan untuk membuktikan bahwa hasil yang didapatkan dari permodelan geometri ini tidak lagi dipengaruhi oleh mesh yang digunakan. Studi grid independent dilakukan dengan memvariasikan jumlah grid baik pada arah longitudinal $(\mathrm{Nx})$ maupun transversal $(\mathrm{Nz})$ untuk kemudian dibandingkan hasilnya dengan hasil dari referensi yang digunakan. Adapun hasil grid independent yang dilakukan dapat dilihat pada Gambar 4 berikut. Dari Gambar 4, untuk eksentrisitas ratio 0.2 terlihat pada mesh number 85,000 ke atas menunjukkan hasil tekanan maksimum yang mulai stabil hingga seterusnya sedangkan eksentrisitas ratio 0.8 terlihat pada mesh number 50,000 keatas menunjukan hasil tekanan maksimum yang mulai stabil. Sehingga pada simulasi ini akan menggunakan jumlah elemen mesh 100,000 (10x10,000).

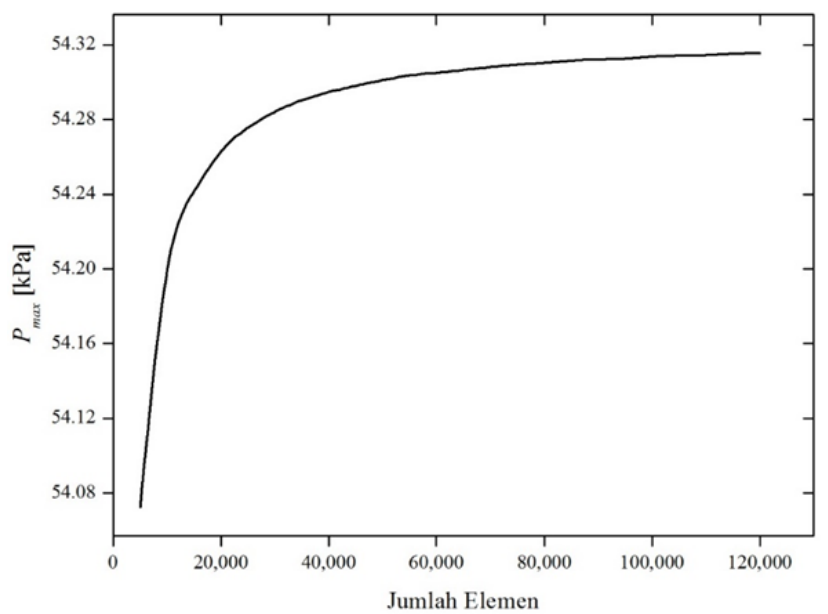

(a)

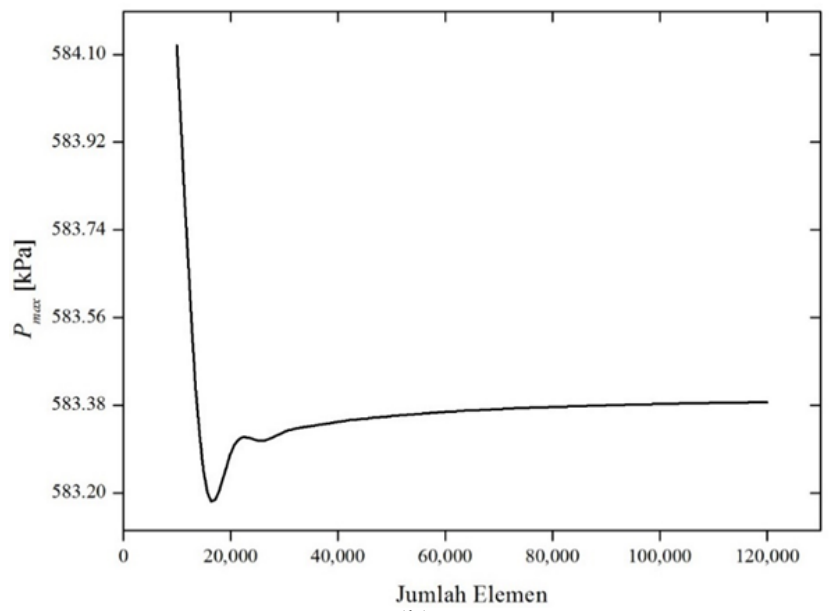

(b)

Gambar 4. Grafik grid independence rasio eksentrisitas (a) 0.2 dan (b) 0.8

\section{Hasil dan Pembahasan}

\subsection{Kasus 1}

Hasil simulasi perhitungan numerik journal bearing dengan $\varepsilon=0.2$ dan $\varepsilon=0.8$ untuk kasus 1 dapat dilihat pada Gambar 5 berikut. Berdasarkan Gambar 5 berikut dapat dilihat bahwa nilai persen error tekanan dan daya dukung beban terbesar terjadi pada kasus journal bearing dengan kondisi batas no slip. Hal ini terjadi karena permaslahan dalam present study diselesaikan oleh Fluent menggunakan persamaan Navier Stokes tanpa mempertimbangkan pengaruh kavitasi pada journal bearing, sedangkan permasalahan yang diselesaikan Wu [3] menggunakan Reynold equation dengan kondisi batas Reynold boundary condition. Untuk mengatasi hal ini maka dilakukan perhitungan daya dukung beban manual dari hasil simulasi software CFD dengan menggunakan pendekatan kondisi batas Half Sommerfield. Dengan menggunakan cara ini dapat diliat bahwa persen error daya dukung beban untuk kasus telah melewati batas persen error diperbolehkan. 


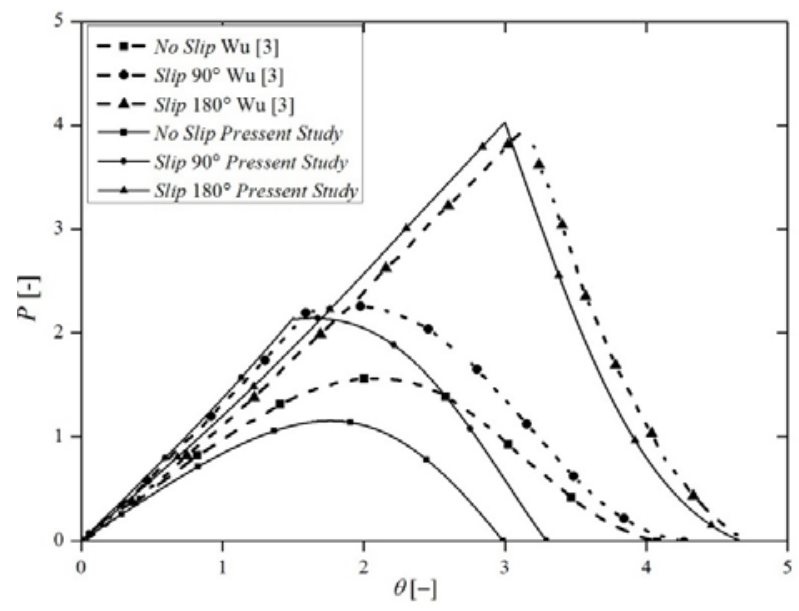

(a)

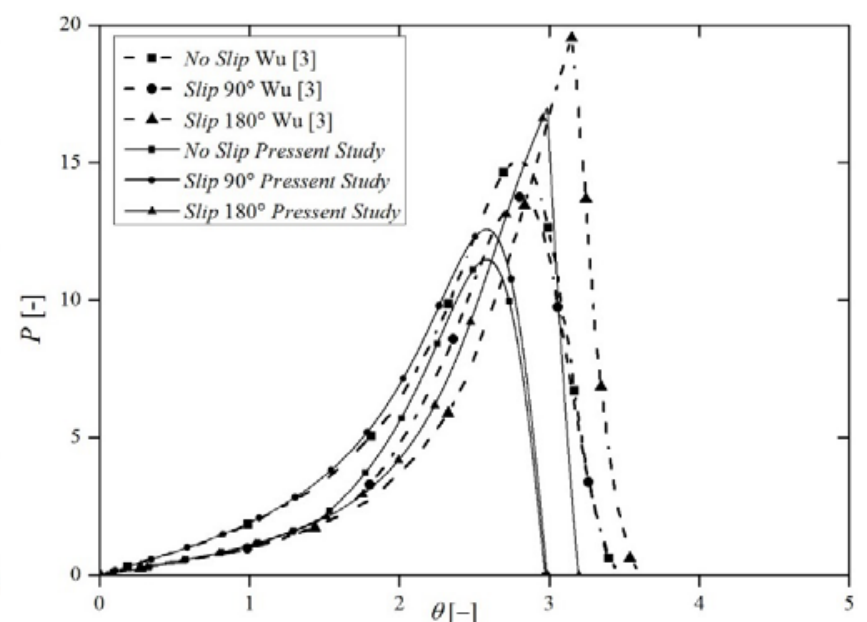

(b)

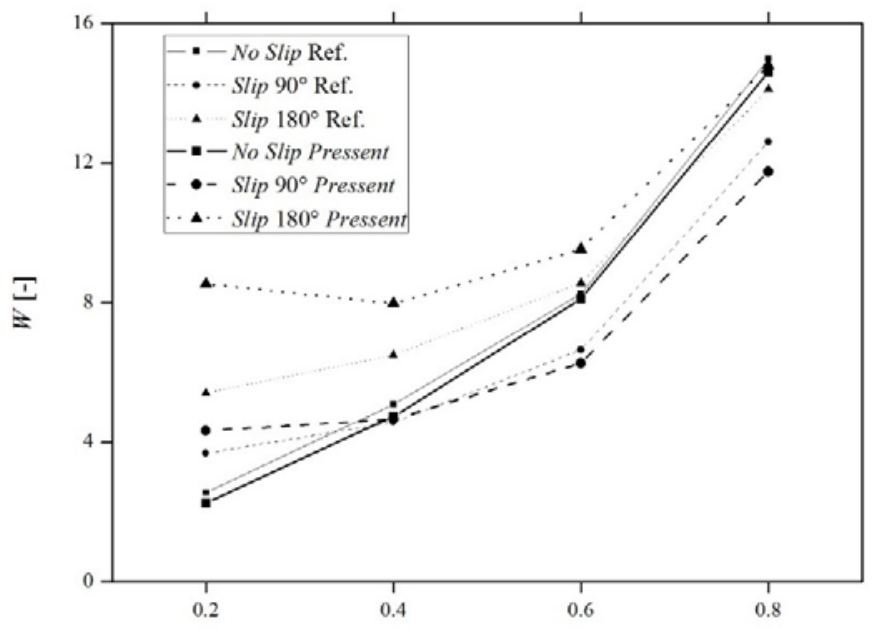

(c)

Gambar 5. Hasil perbandingan (a) Distribusi tekanan $\varepsilon$ 0.2, (b) Distribusi tekanan $\varepsilon 0.8$ dan (c) Load support setiap rasio eksentrisitas

\subsection{Kasus 2}

Pada kasus ini, hasil load support merupakan hasil perhitungan manual dari rumus $W=\sum\left(\int_{1}^{2} p d x\right)$ dengan pendekatan Half Sommerfeld. Pada Gambar 6b didapat bahwa nilai load support tertinggi pada eksentrisitas rasio 0.2 yaitu slip $0^{\circ}-240^{\circ}$, pada eksentrisitas rasio 0.4 yaitu slip $0^{\circ}-210^{\circ}$, pada eksentrisitas rasio 0.6 yaitu slip $0^{\circ}-180^{\circ}$, pada eksentrisitas rasio 0.8 yaitu slip $0^{\circ}-180^{\circ}$.

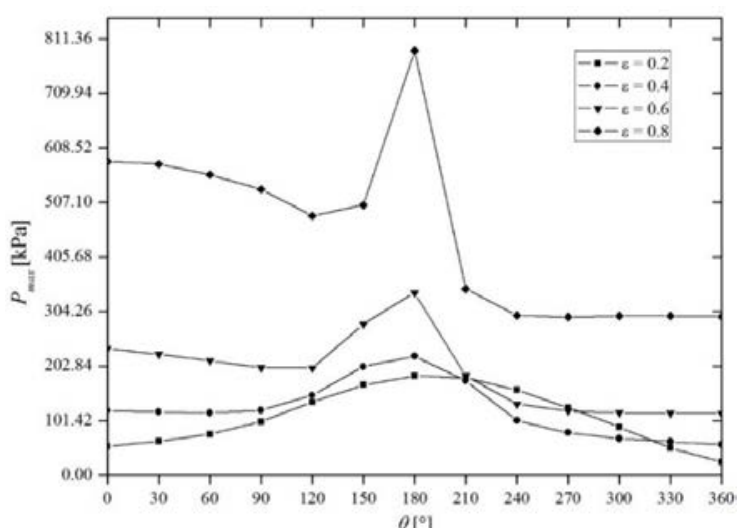

(a)

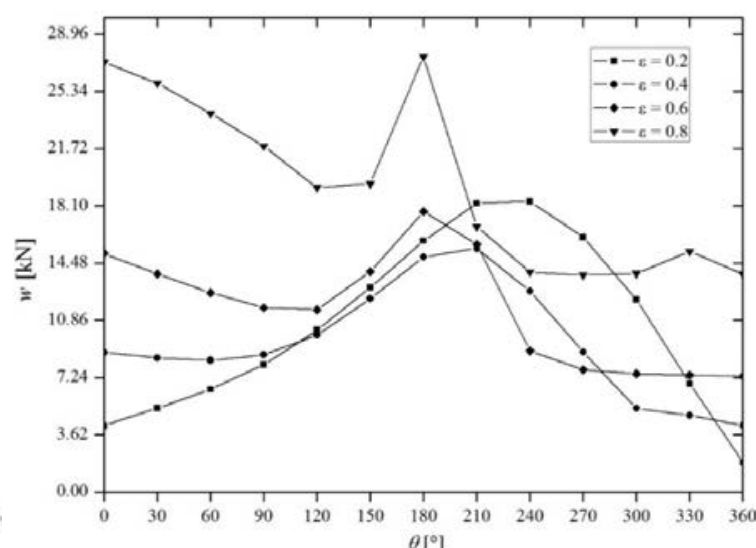

(b) 


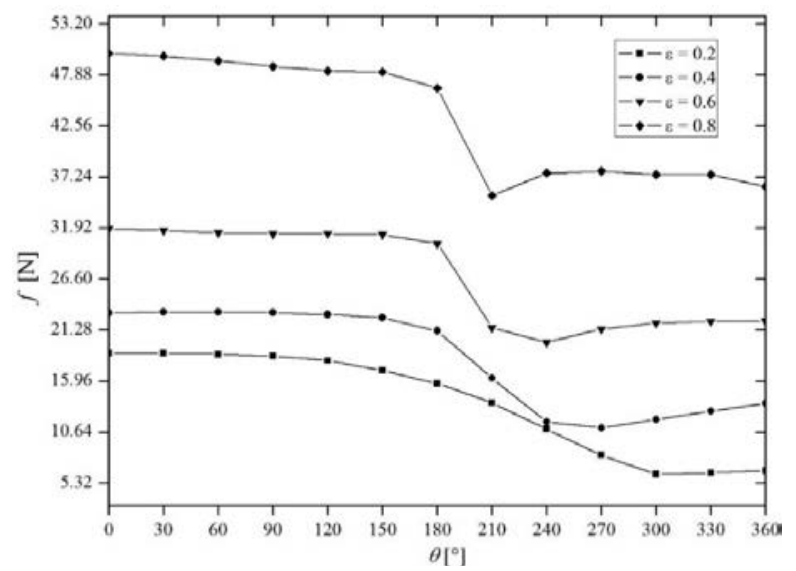

(c)

Gambar 6. Hasil performa pelumasan (a) Pressure maximum, (b) Load support dan (c) Friction pada setiap eksentrisitas rasio

Gaya gesek dihasilkan dari sistem pelumasan karena gaya viskos fluida dan dihitung oleh software CFD dengan mengintegralkan tegangan geser pada permukaan sepanjang area bearing. Pada Gambar 6c didapat bahwa nilai gaya gesek terkecil pada eksentrisitas rasio 0.2 yaitu slip $0^{\circ}-300^{\circ}$, pada eksentrisitas rasio 0.4 yaitu slip $0^{\circ}-270^{\circ}$, pada eksentrisitas rasio 0.6 yaitu slip $0^{\circ}-240^{\circ}$, pada eksentrisitas rasio 0.8 yaitu slip $0^{\circ}-210^{\circ}$. Semakin besar eksentrisitas rasio, hasil gaya gesek terkecil mengalami pengecilan penempatan slip seperti pada eksentrisitas rasio 0.2 terdapat pada slip $0^{\circ}-300^{\circ}$ sedangkan eksentrisitas rasio 0.8 terdapat pada slip $0^{\circ}-210^{\circ}$.

\section{Kesimpulan}

Setelah melakukan serangkaian simulasi menggunakan software CFD pada dua kasus permukaan journal bearing, diperoleh kesimpulan dari hasil simulasi tentang optimasi peformasi pelumasan mengenai efek pemberian slip pada journal bearing dengan menggunakan software CFD adalah :

1. Pemodelan slip menggunakan software CFD telah dilakukan. Dari hasil penelitian dapat diketahui bahwa simulasi numerik yang dilakukan memiliki kesesuaian dengan hasil riset Wu [3]. Grafik tekanan dan load support memiliki tren yang sama dengan hasil riset $\mathrm{Wu}$ [3].

2. Pemberian slip pada permukaan journal bearing sangat berpengaruh pada performa pelumasan terutama pada distribusi tekanan, load support dan friction.

3. Bedasarkan hasil dari variasi pemberian slip, nilai load support tertinggi pada $\varepsilon 0.2$ dan $\varepsilon 0.4$ dengan penempatan slip untuk $\varepsilon 0.2$ pada slip $0^{\circ}-240^{\circ}$ dan $\varepsilon 0.4$ pada slip $0^{\circ}-210^{\circ}$. Sedangkan friction terkecil terjadi pada $\varepsilon 0.2$ pada slip $0^{\circ}-300^{\circ}, \varepsilon 0.4$ pada slip $0^{\circ}-270^{\circ}$, $\varepsilon 0.6$ pada slip $0^{\circ}-240^{\circ}$ dan $\varepsilon 0.8$ pada slip $0^{\circ}-210^{\circ}$.

\section{Referensi}

[1] Nikolic, N., Jovan, D., Zivota, A., 2015, Some Aspects of Temperature Distribution in IC Engine Crankshaft Bearing. $17^{\text {th }}$ Symposium on Thermal Science and Engineering of Serbia. 20-23 Oktober. Sokobanja, Serbia.

[2] Spikes, H.A., Granick, S., 2003, Equation for Slip of Simple Liquids at Smooth Solid Surfaces. Physical Review Letters. Vol. 19, No. 12, pp. 5065-5071.

[3] Sularso \& Kiyokatsu S., 2004, Dasar Perencanaan dan Pemlihan Elemen Mesin. Jakarta: PT. Pradyna Paramita.

[4] Doshi, H., 1998. Range Bearing, Techno Overseas, Maharashtra, India, http://www.fkpillowblock.com. 9 November 2017 (13.45).

[5] Scott, R., 2005, Journal Bearings and Their Lubrication. Machinery Lubrication Magazine. http://www.machinerylubrication.com. 10 November 2017.

[6] Chauhan, A., Rakesh, S., 2012, Thermal Studies of Non-Circular Journal Bearing Profiles: Offset-Halves and Elliptical. Performance Evaluation of Bearings, Dr. Rakesh Sehgal (Ed.). UnTech, DOI: 10.5772/51261. Available from: https://www.intechopen.com/books/performance-evaluation-of-bearings/thermal-studies-of-noncircular-journal-bearing-profiles-offset-halves-and-elliptical.

[7] Kurniawan, B., 2012, Analisis Pengaruh Kekasaran Permukaan dan Slip Terhadap Performasi Pelumasan Journal Bearing Menggunakan Metode Volume Hingga, Skripsi, Universitas Diponegoro, Semarang, Indonesia.

[8] McKee, S.A., McKee, T.R., 1932, Journal Bearing Friction in the Region of Thin Film Lubricatio. Journal Society of Automotive Engineers Technical Paper. Vol. 31, No.1, pp. 371-377.

[9] Robert, W.F., Alan, T.M., 2004. Intoduction to Fluid Mechanics 6th Edition. USA: John Wiley \& Sons Inc.

[10] Harnoy, A., 2003, Engineering Tribology and Lubrication. USA: Marcel Dekker, Inc. 
[11] Zulfikar, A., 2010, Optimasi Daerah Slip pada Permukaan Bertekstur pada Pelumasan MEMS (Micro Electro Mechanical System), Skripsi, Universitas Diponegoro, Semarang, Indonesia.

[12] Xie, Z.L., 2017, The Lubrication Performance of Water Lubricated Bearing with Consideration of Wall Slip and Inertial Force. Journal of Hydrodynamics. Vol. 29, No. 1, pp. 52-60.

[13] Zhu, Y., Granick, S., 2001, Rate-Dependent Slip of Newtonian Liquid at Smooth Surface, Physical Review Letters. Vol. 87, No. 9, pp. 96-105. 